\title{
Understanding teachers' routines to inform classroom technology design
}

\author{
Pengcheng An ${ }^{1} \cdot$ Saskia Bakker ${ }^{1} \cdot$ Berry Eggen $^{1}$
}

Published online: 12 May 2016

(C) The Author(s) 2016. This article is published with open access at Springerlink.com

\begin{abstract}
Secondary school teachers have quite busy and complex routines in their classrooms. However, present classroom technologies usually require focused attention from teachers while being interacted with, which restricts their use in teachers' daily routines. Peripheral interaction is a human-computer interaction style that aims to enable interaction to take place both in the center and periphery of users' attention and naturally shift between the two. We believe that classroom technologies employing the principles of peripheral interaction can reduce attentional resources required for teachers to interact with the technologies, and thus make technologies seamlessly blend into teachers' routines. In order to design such technologies, a thorough understanding of users' existing routines is crucial. In this paper, we present a qualitative study on everyday routines of seven Dutch secondary school teachers using contextmapping methodology. The results of two qualitative content analyses reveal an overview of teachers' routine tasks in their classrooms, as well as rich and vivid contextual information about how teachers allocated their attention in their routines and how teachers experience their routines. Based on these findings, we present opportunities and considerations that may inform the design and development of classroom technologies which are to become part of teachers' routines.
\end{abstract}

Keywords Classroom technology $\cdot$ Secondary school teacher $\cdot$ Routine $\cdot$ Peripheral interaction $\cdot$ Contextmapping $\cdot$ Stimulated recall interview

Pengcheng An

p.an@tue.nl

1 Department of Industrial Design, Eindhoven University of Technology, P.O. Box 513, 5600 MB Eindhoven, The Netherlands 


\section{Introduction}

Secondary school teachers usually have quite busy everyday routines. During a lesson, they need to perform various tasks including interacting with 30 or more students and using different artefacts (e.g. whiteboard, computer, documents and timers) in order to successfully organize classroom activities. Frequently, a teacher needs to divide attention or switch between doing different tasks. For example, a teacher may be reading texts to students while at the same time observing if students are paying attention, or a teacher might need to answer a question from a student while in the middle of helping another student. As a result of busy routines teachers have, they are not always able to serve all the students equally, e.g. if there are several hands of students' in the air requiring the teacher's attention at one moment, the teacher has to choose who to help. Among other things due to these scenarios, teachers' work has been considered increasingly complex and intensive (Brante 2009).

Technologies are making their way into classrooms. Computing artefacts such as laptops, tablet computers, mobile devices, interactive whiteboards, augmented school desks and tangible interfaces (Antona et al. 2010; Beauchamp 2004; Horn and Jacob 2007; Stanton et al. 2001), are being used and developed to facilitate both teaching and learning. Technologies can valuably support teachers' work, e.g. by making the lessons more appealing to students, giving access to diverse up-to-date resources, and effecting working processes to increase students' productivity (Ruthven et al. 2004). Along with many opportunities, these emerging technologies also bring challenges to teachers' work. More human-computer interfaces usually means even more tasks to perform, and more objects to attend to. Supporting technologies often unintentionally bring new complexity to teachers' work (Cuban et al. 2001), which makes it challenging for teachers to successfully adopt such technologies as part of their existing busy everyday routines. Although schools, in developed countries, are normally well equipped with ICT infrastructure, computers still remain relatively infrequently used for educational purposes (Urhahne et al. 2010). The reality of "high access and low use of technology in schools" (Cuban et al. 2001) reveals a gap between present technology and teachers' work in the classroom. This gap is partly caused by restricted and inconvenient access to the technologies and partially by the time pressure experienced by teachers (Becker 2000; Cuban et al. 2001). In other words, those technologies do not seem to fit well into teachers' busy everyday routines because of the effort and time required to use them. It is therefore deemed important to take the context and routines of teachers into account in order to design successful classroom technologies to facilitate teachers' work.

Undoubtedly, computing technology has great potential to support teachers' work. However, we believe that such technology can only successfully blend into teachers' busy everyday routines, when their interaction designs demand only limited attentional resources. We believe this can be achieved by relying on the principles of peripheral interaction (Bakker et al. 2014), an interaction paradigm inspired by calm technology (Weiser and Brown 1997). By enabling interaction both in the background, or periphery, and in the center of a user's attention, and allowing frequent shifts between the two, "peripheral interaction design can support computing technology to fluently embed in and become a meaningful part of people's everyday routines" (Bakker et al. 2014, p. 239).

In order to successfully design such peripheral interaction systems for teachers, a thorough understanding of existing routines (Bakker et al. 2014) in classrooms is 
essential. Routines are seen as "the very glue of everyday life" (Tolmie et al. 2002, p. 399), since they encompass an enormous amount of our everyday actions and put them coherently together like one threads beads on a string, thus making our everyday actions unremarkable and unhesitating. It is estimated by researchers (Dean 2013; Wood et al. 2002) that half of our daily lives consist of performance of routine behaviors which are habituated and intuitive, so that we do not have to allocate much attention on them. We believe that a detailed understanding of routines in the context is crucial as input for developing interaction design which can be successfully used as part of teachers' everyday work. In particular, a detailed understanding of teacher's tasks and allocation of attention in those routines is needed. While various related studies have aimed to explore and develop new technologies for classroom use, no related work is known to the authors, which focuses on revealing vivid contextual and experiential information about classroom routines of teachers to inform the design and development of classroom technology.

With the aims of gaining rich contextual insights in teachers' everyday routines as input for interaction design, we present a qualitative study on the daily routines of 7 Dutch secondary school teachers, using the contextmapping methodology (Visser et al. 2005). This study addresses the following research questions: 1. What tasks do teachers do as part of their everyday routines? 2. How do teachers allocate their attention during their everyday routines? 3. How do teachers experience their everyday routines?

In this paper, we will first address related work on classroom technology and explorations of teachers' everyday routines. Subsequently, we will describe how we implemented the contextmapping methodology and qualitative content analysis (Hsieh and Shannon 2005) in our study, after which results from two analyses will be presented and discussed. Finally, we will present design opportunities based on our study results, which can support human-computer interaction to better blend into the everyday routines in secondary school classrooms.

\section{Related work}

\subsection{Classroom technologies}

The majority of today's secondary school classrooms, in developed countries, have (laptop) computers, smartboard and Internet facilities present (Brummelhuis et al. 2015). Mobile devices such as tablet computers and smartphones are being increasingly used in classrooms as well, and numerous software applications are commercially available to help teachers in various activities such as organizing the class (e.g. Class Dojo, https://www.classdojo.com/), explaining class exercises (e.g. Socrative, http:// www.socrative.com/) and taking notes (e.g. Clear, http://realmacsoftware.com/clear/).

However, running on laptops, tablets and smartphones, these applications require teachers to visually focus on the graphical user interfaces to accomplish successful interactions. For example, if a teacher wants to take a note after observing a certain student's performance when walking around the classroom, the teacher may have to take a mobile phone out of his or her pocket, unlock the screen, locate the icon of the note-taking application, and add a new note, before he or she can input the content. 
During the whole process, the teacher has to pay attention to the interaction with the touchscreen and valuable time to devote to supporting students is lost.

While a lot of studies on designing classroom technologies focus on facilitating learning activities (e.g., Bodén et al. 2013; Charoenying 2008; da Silva et al. 2011; Sylla 2013; Zhang et al. 2010), only few research explorations also concern designing interactions which demand limited attentional resources from users (the teacher or the students). These works are known in the areas of ambient displays displays designed to present information without requiring focused attention of users (Pousman and Stasko 2006) -, tangible user interfaces - interfaces provide users tangible representations of digital data to interact with (Shaer 2009) - and peripheral interaction (Bakker et al. 2014). Some examples of these related classroom technologies will be addressed below.

Lamberty et al. (2010) introduced an ambient display which aims to support elementary school students to remain aware of what their peers are doing when they are all working on an individual computer to solve design challenges related to fractions and symmetry. The ClassSearch system (Moraveji et al. 2011) offers the teacher and students awareness of Web search activities in the classroom to facilitate social learning and teacher-led discourse by means of an ambient display. Sturm et al. (2006) described an unobtrusive service providing the teacher feedback of the attention level as well as the interest level of students through an ambient display while he or she is lecturing. Alavi and Dillenbourg (2012) addressed a system with interactive lamps called Lantern that means to facilitate interaction between tutors and students working in teams by displaying ambient information about work status of each team. van Alphen and Bakker (2015) presented Lernanto, an ambient display of each student's real-time performance based on their own levels as well as the subject one is working on to help the teacher to give differentiated instructions by easily perceiving the students' information at a glance.

Above are examples of explorations on designing classroom technologies, which display relevant information to students and teachers that can be perceived without focused attention. Some devices are also known which can be manipulated by users (the teacher or the students) at a low attentional level. For example, Subtle Stone (Alsmeyer et al. 2008) is a device that enables each student to communicate their emotional experience to the teacher in real time during the lesson, by easily squeezing a handheld orb containing LED lights. Bakker et al. (2012) addressed several technologies designed for primary school teachers as attempts of peripheral interaction in the context of classrooms. For example, Notelet (Bakker et al. 2014) is an interactive bracelet for the teacher to wear around the wrist, with which the teacher can actuate a camera mounted in a corner of the classroom to take a picture of the classroom at the moment the teacher wanted to record a certain behavior of a student. FireFlies (Bakker et al. 2013) is an interactive system, consisting of a light-object for each student and a tangible teacher tool with small beads mapping to each light-object to control the color of light-objects both separately and collectively. Teachers can use this system to quickly and silently communicate short messages to children during busy classroom situations.

The related work discussed presents explorations of classroom technologies designed to demand limited attentional resources while being interacted with. These examples indicate that peripheral interaction, enabling human-computer interaction to take place in both the periphery and the center of the user's attention, is a promising 
direction to more fluently embed supportive technology in the everyday routines in the classroom. In order to more systematically explore and develop technologies that can effortlessly merge into teachers' everyday routines, we believe the next step is to gain a solid understanding of teachers' existing everyday routines, enabling us to lay out opportunities for the development of multiple supportive technologies that leverage peripheral interaction. Since no related research is known to the authors that presents the required contextual insights, this paper presents a qualitative contextmapping study to reach these aims.

\subsection{Teachers' routines}

A number of related studies on teachers' routines are known in the area of ComputerSupported Collaborative learning (CSCL). Greiffenhagen (Greiffenhagen 2011), for example, analyzed teachers' work during collaborative learning activities to find out how teachers intervene in pupils' learning. Prieto et al. (Prieto Santos et al. 2015) presented a study on teachers' 'orchestration load' (the mental load required to facilitate CSCL activities in daily work) using mobile eye-tracking technology in both a lab and a field setting, finding that the increased load for teachers to facilitate and monitor CSCL activities can be challenging for CSCL practice.

Other related studies on teachers' routines are known in the areas of educational science and sociology. Some studies investigate teachers' routines out of class. For example, Yinger (2009) has studied teachers' routines in 'preactive teaching', which takes place before or after class when the teacher is alone. Aili and Brante (2007) presented a study on teachers' non-classroom (tuition-free) work to see how teachers employ their professional knowledge in studied situations. Other studies have explored teachers' activities during lessons. For example, Doyle (1977) presented results of an ecological analysis about activities in classroom environment, which indicated that teachers have to face multidimensionality, simultaneity, and unpredictability in the classroom and in turn develop strategies to reduce the complexity of their work. Golombek (1998) studied how the personal practical knowledge of teachers informed their practice in classrooms using class observations, interviews and stimulus recall reports. In another study, Brante (2009) gathered data of teachers' multitasking behaviors to investigate teachers' busy work conditions and suggested to have fewer pupils per class and encourage teachers to talk about how to improve the situation in the local school.

The mentioned studies in the area of CSCL revealed interesting aspects of teacher routines in CSCL activities. Whereas they focus on the application of technologies in CSCL settings, the study presented in this paper aims to investigate mainstream secondary school classrooms where various types of teaching and learning activities take place. While being setup from an educational or sociological perspective, the other related studies we discussed above have also provided insights into our work. Specifically, they delineated some attributes of teachers' routines, such as simultaneity (highlighting that multiple activities need to be done at the same moment) (Doyle 1977), complexity, intensity and multitasking (Brante 2009). These factors - describing teacher's routines as being rather busy and complex - indicate that designing classroom technologies, which avoid imposing a high attentional burden on teachers, seems meaningful. Therefore, inspired by these related studies, the study presented in this 
paper further investigates the context from a design perspective using contextmapping methodology (Visser et al. 2005) to contribute insights on classroom routines of secondary school teachers, as well as considerations which can be applied by classroom technology designers and design-researchers, who aim to fluently embed their designs into teachers' routines.

\section{Methodology}

\subsection{Contextmapping methodology}

The purpose of the study presented in this paper is to gain a rich contextual understanding of teachers' everyday routines in order to inform the design of classroom technologies which are to become a part of these routines. We conducted the study, using the methodology of contextmapping (Visser et al. 2005). This method is developed to extract the experience and 'latent needs' of users to inspire or improve product design, but has also been used by researchers to study people's hidden experiences or subconscious behaviors (Bakker et al. 2011; Offermans et al. 2014). Contextmapping consists of two phases: the sensitization phase and the group session phase. In the sensitization phase, participants individually perform exercises in their home or work environment over the course of a few days, to prepare or 'sensitize' them for the topic of the study. In the group session phase, participants take part in group discussions and participatory activities to reflect on and express their thoughts, feeling, and experiences regarding the topic of the study, often through the making of artefacts or collages (Visser et al. 2005).

Everyday routines are often 'unremarkable' (Tolmie et al. 2002); they have been repeated so many times in daily life that people are usually not aware of the details of their daily routines. For example, we can easily remember what dinner we have prepared yesterday, but we may find it difficult to clearly recall in detail how we attended to and interacted with the objects around us in our kitchen. Similarly, if asked about their everyday routines, teachers likely easily remember the content of lessons, but it may not be easy for them to explain the details of how they divide or switch their attention to accomplish different tasks in their lessons. We therefore decided to use the method contextmapping, which enables participants to be sensitized towards their routine experiences that normally go unnoticed before we ask them about these experiences in a group discussion, as also applied in (Bakker et al. 2011). Additionally, the contextmapping method enabled us to gather insights and inspiration for the design of classroom technologies through creative participatory techniques used in the group session.

\subsection{Participants}

For this study we recruited seven secondary school teachers in The Netherlands as participants. As Table 1 shows, at the moment of the study, P1, P2, and P7 were working in the same school (school S1), while P4, P5, and P6 were each employed at a different school (schools S2, S3, and S4, respectively). P3 recently graduated as a teacher and was at the moment of the study pursuing a graduate degree. This number of 
Table 1 Participant demographics

\begin{tabular}{llllll}
\hline Participant & Gender & Age & $\begin{array}{l}\text { Teaching } \\
\text { experience (years) }\end{array}$ & Subject(s) taught by the participant & School \\
\hline P1 & F & 61 & 15 & Music & S1 \\
P2 & F & 61 & $>30$ & English & S1 \\
P3 & M & 24 & 1 & Physics & - none- \\
P4 & M & 35 & 10 & Mathematics, Computer Science & S2 \\
P5 & F & 46 & 9 & Chemistry, Physics, Science & S3 \\
P6 & M & 34 & 6 & Information science, Applied Engineering & S4 \\
P7 & F & 36 & 12 & Spanish & S1 \\
\hline
\end{tabular}

participants is within the range of recommended numbers of participants for contextmapping studies (Visser et al. 2005), and was expected to allow for in-depth exploration of individual's routines. To increase the reliability of this qualitative research, we chose to recruit a varying group of teachers which was divers in gender, age, teaching experience and teaching subjects as also shown in Table 1. We believe by doing this the gathered data could cover a wide range of classroom routines of secondary school teachers.

\subsection{Study design}

Following the contextmapping method, our study consisted of a sensitizing phase and a group session phase. We decided to use two different approaches to sensitizing: a stimulated recall interview and an exercise booklet.

\subsubsection{Sensitization phase 1: Stimulated recall interview}

In the first part of the sensitizing phase, we chose to use a stimulated recall interview (SRI), an interview technique in which a video of a participant's behavior in a real-life setting is recorded, after which the participant is interviewed while playing back the recording (Dempsey 2010). Our reason for using the SRI technique is twofold. First, as mentioned before, people are usually not consciously aware of their routine behaviors in everyday life. By looking at and reflecting on the recording, each participant likely becomes more aware of his or her own routines, sensitizing them for the group session. Second, the recordings and particularly participants' reflections on these recordings can give us a rich understanding of not only which tasks are part of teachers' everyday routines, but also what they are attending to, what they are thinking about, and what the meanings of their actions are.

While some of the participants taught more than one subject at the moment of the study, only one class among the subjects was recorded for the stimulated recall interview (see Table 2). Before each stimulated recall interview, one 50-min lesson of each participant was recorded on video. A digital camera was placed in the back of the classroom. Additionally, a researcher was sitting at the back of the classroom to silently observe the participant and take notes of moments that might be selected as video clips 
Table 2 Participation of the participants

\begin{tabular}{lllll}
\hline Participant & Subject of lesson recorded for SRI & Participation & & \\
\cline { 3 - 5 } & & Stimulated Recall & Exercise Booklet & Group Session \\
& & Interview & \\
\hline P1 & Music & $\sqrt{ }$ & $\sqrt{ }$ & $\sqrt{ }$ \\
P2 & English Language Literature & $\sqrt{ }$ & $\sqrt{ }$ & $\sqrt{ }$ \\
P3 & -none- & & $\sqrt{ }$ & $\sqrt{ }$ \\
P4 & Mathematics & $\sqrt{ }$ & $\sqrt{ }$ & $\sqrt{ }$ \\
P5 & Chemistry & $\sqrt{ }$ & $\sqrt{ }$ & $\sqrt{ }$ \\
P6 & Information science & $\sqrt{ }$ & $\sqrt{ }$ & \\
P7 & Spanish & $\sqrt{ }$ &
\end{tabular}

to play back in the interview. For the recorded music lesson of Participant P1, the observer had to take the camera and follow the teacher sometimes, since the teacher had to change her positions among the main classroom, and several rehearsal rooms every now and then to help students while teaching. Participant P3 did not participate in the stimulated recall interview because he was not employed as a teacher at the moment of the study. For participants P6, only 30 min of the lesson could be recorded due a sudden change of the teacher's schedule.

Interviews were conducted in English. Each interview was conducted as soon as possible after the recorded lesson, so that the participant had fresh memories about the lesson. In each case, the interval between the lesson and the interview was less than one and a half hours. In between the lesson and the interview, the researcher watched the video and selected five to seven clips to be played in the interview. Each video clip lasted one to three minutes. The video clips were selected to cover different class activities (e.g. moments in which the teacher provided whole-class instructions or lectures, moments in which he or she facilitated students' working, fragments in which the teacher walked around the classroom, and footage of participants interacting with the interactive whiteboard or computers) as well as different time periods of the lesson. This way, the interviews would cover a comprehensive overview of the teachers' routines.

In each stimulated recall interview, the selected video clips were played to the participant in chronological order. While watching each video clip, the participant was asked to explain what was happening in the video, using questions such as: "What are you doing now?" "What is in your mind right now?" "Where do you put your attention?" "What do you see?" and "What do you hear?". Depending on the speed of speaking of the participants, the researcher would, at moments, pause or replay parts of a clip. Each interview lasted around $30 \mathrm{~min}$. The interviews were audio-recorded for analysis.

\subsubsection{Sensitization phase 2: Exercise booklet}

After the stimulated recall interview, each participant was given a sensitizing booklet (shown in Fig. 1) with four exercises. They were asked to perform each exercise on a separate day whenever it suited them (either at school or at home). Each exercise was 


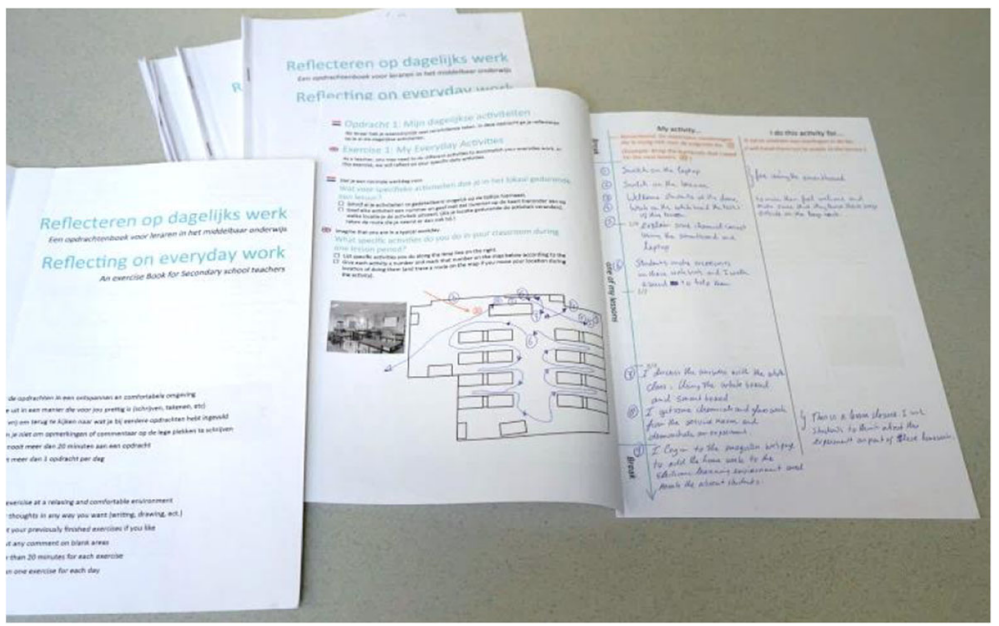

Fig. 1 Exercise booklets used for sensitization

designed to take less than $20 \mathrm{~min}$. It took one to two weeks for each participant to complete the booklet before it was handed back to the researchers. Texts on the booklets were in both English and Dutch, the participants could choose either language to fill in the booklets.

The aim of using a sensitizing booklet is similar to that of using the SRI technique, which is to sensitize participants about their unremarkable routine behaviors that they are normally not consciously aware of, so that in the group sessions they can more insightfully discuss about the tacit knowledge (Visser et al. 2005) that they act upon in their daily routines. Different from the SRI technique, sensitizing booklets trigger participants to reflect on their own behaviors with less intrusion (participants keep and complete the booklets by themselves) and more freedom (participants can choose suitable places and time to finish the exercises) during longer periods of time (one to two weeks in our case) before the group sessions.

In line with the contextmapping method, the four exercises were designed to help participants to gradually reflect on easy aspects (daily activities and daily objects) to more difficult ones (teachers' multitasking behaviors and their experiences on them). In the first exercise, the teachers were triggered to reflect on their conventional class activities, by listing a chronological overview of their activities during one typical lesson along a timeline printed on one page of the booklet. They were also asked to mark locations of their activities and draw curves indicating their footprints of doing those activities on a layout map of their classrooms. In the second exercise, the teachers were encouraged to think about various everyday tools (e.g. mark pen, whiteboard, laptop computer, or mobile phone) they use in their classrooms, by describing the usage of each tool. A layout map was also provided for participants to indicate the locations of using those tools. In the third exercise, teachers were asked to reflect on moments at which they did more than one thing at the same time (multitasking), by describing examples from their own experience. The final exercise asked teachers to think about their effortful and effortless situations when doing tasks in their classrooms.

The booklets were collected from participants before the group sessions. Information filled by the participants was used in the preparation of these sessions. 


\subsubsection{Group session}

After the sensitization phase, each participant joined a group session. Three such sessions were conducted, each in English, and each with two participants. One teacher (P7) could not participate in a group session due to unforeseen circumstances. The interval between the recall interview and the group session for each participant was 1 to 3 weeks. Two group sessions were conducted in a meeting room at the university and one session was held in a classroom of a secondary school where the two participants worked. Snacks and drinks were offered to the participants to create a relaxing trustful atmosphere.

Each session lasted for about one and a half hour, and mainly contained three parts: a group discussion and two collage making activities. The sessions were recorded on video for later analysis, and were scheduled as follows:

Introduction (5 $\mathrm{min}$ ): To start the session, the researcher gave a brief introduction about the setup of the group session, and let the two participants introduce themselves to each other.

Group discussion (30 min): The exercise booklets from the sensitizing phase were given back to each participant, after which a group discussion started. The discussion consisted of four parts, corresponding to four exercises in the booklet. First, participants were asked to look at their lists of class activities in the first exercise of their booklets, and reflect on what their busiest moments are in their lessons. Second, based on the tools they listed in the second exercise in their booklets, participants were asked to discuss how they use these tools in their lessons. Third, participants were asked to share and discuss examples of multitasking behaviors. And fourth, participants were asked to talk and reflect on situations in their routines they find difficult or effortless.

Break (10 min)

Collage making: experience teaching $(25 \mathrm{~min})$ : After a break, the first collage making exercise was introduced. We chose to have two collage making activities because collages are a low-threshold means of expressing (latent) thoughts and experiences for people who are not experienced in the fields of creativity and design (Visser et al. 2005). In this collage each participants was given a set of sheets on which 150 words and 200 pictures were printed. They were asked to use these words and pictures to make a collage that expresses their thoughts, feelings and experiences regarding their everyday routines in the classroom (see Fig. 2). They were given $15 \mathrm{~min}$ to make the collage and $5 \mathrm{~min}$ for each to explain their collage to the group.

Break (5 min)

Collage Making: robot fantasy $(25 \mathrm{~min})$ : After a short break, the second collage making activity started. Each participant was given a set of sheets depicting images of robot parts and of different kinds of daily objects, which teachers may use in daily work (such as electronic devices and stationery equipment). The participants were asked to use these images to design a robot that could help them in their daily routines in the classrooms, by cutting out and sticking together these images on an empty sheet (see Fig. 3) in 15 min. After creating their robot, each participant were asked to explain how his or her robot would help him or her in $5 \mathrm{~min}$. The purpose of this collage making activity is to help teachers in exploring their latent needs for 


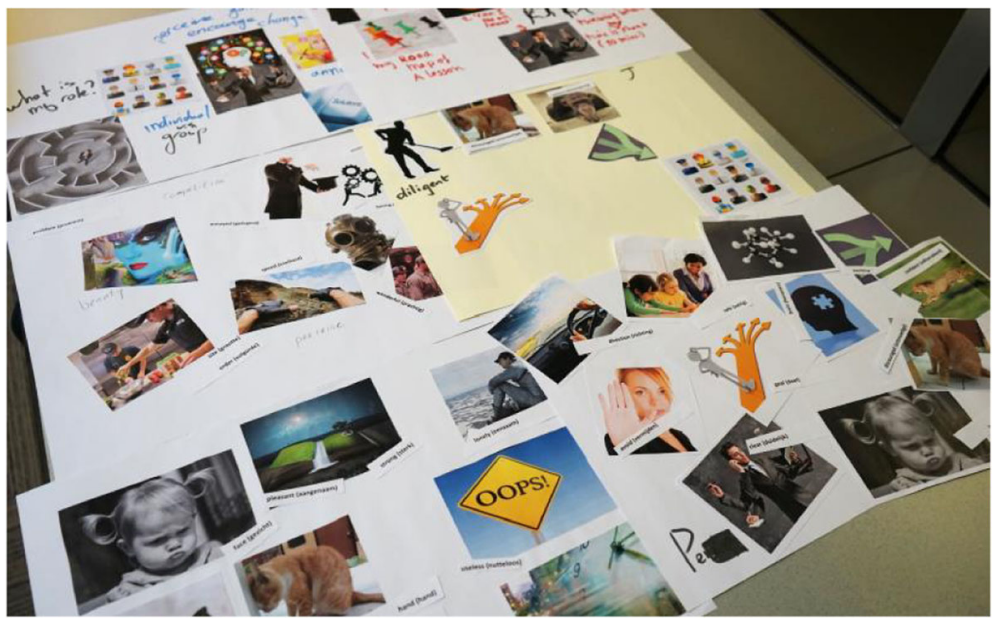

Fig. 2 Collages made by participants in the first collage making activity: experience teaching

classroom technologies, which can provide insight into the experience of their everyday routines. Additionally we included this exercise to serve as inspiration for future classroom technology design, however, these inspirational outcomes are out of the scope of this paper.

\subsection{Data analysis}

\subsubsection{Analysis approach}

The aim of the study described in this paper is to help designers and developers of classroom technologies gain contextual and vivid understanding about routines of

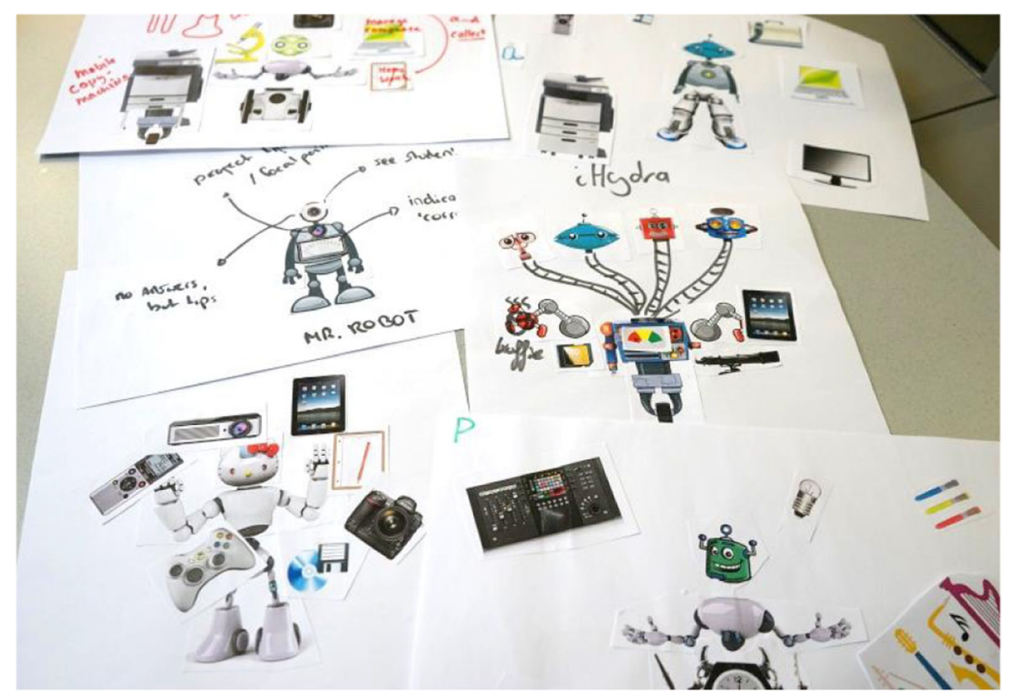

Fig. 3 Collages made by participants in the second collage making activity: robot fantasy 
secondary school teachers into which the technologies are supposed to be blended. According to our research interest, what we want to extract from the data is an overview of teachers' mundane tasks in the classroom and lived experiences and vivid images about how they allocate their attention while fulfilling the tasks, as well as how they experience their routines.

The study yielded various types of qualitative data (including videos, audio records, filled in exercise booklets, and collages). Contextmapping commonly leads to "rich, lively and varied", but "a complex set" and "not readily structured" data (Visser et al. 2005 , p. 133). In order to gain structured insights from our study we analyzed the data gathered using qualitative content analysis (Hsieh and Shannon 2005). This approach helps gain knowledge and understanding of the phenomenon being studied through semantic classification of the quotes selected from verbal data to identify themes or patterns of the data from a naturalistic paradigm (Hsieh and Shannon 2005). To enable analysis, we transcribed all audio and video data from stimulated recall interviews and group sessions verbatim.

\subsubsection{Analysis process}

Our study means to answer the following research questions: 1 . What tasks do teachers do as part of their everyday routines? 2. How do teachers allocate their attention during their everyday routines? 3. How do teachers experience their everyday routines? To answer these questions, we conducted two qualitative content analyses on the data gathered in our contextmapping study. The first analysis, which we will refer to as the routine tasks analysis, aimed to answer research question 1. For this routine tasks analysis we analyzed the transcripts of the stimulated recall interviews in which teachers reported and reflected on their behaviors while looking at a video recorded in their classroom. The second analysis, which we will refer to as the routine experience analysis, aims to answer research questions 2 and 3. For this analysis, we analyzed the transcripts of both the stimulated recall interviews and group sessions.

Selecting quotes Following the qualitative content analysis approach, we selected quotes from the transcripts that related to our research questions. While selecting, we also labeled the quotes based on their content, to get an initial overview of possible categorizations of quotes.

For the routine task analysis we selected quotes from the SRI transcripts that mention a task of a teacher. A task can include bodily movements, such as writing on the whiteboard, a perceptual action, such as looking around the classroom, or a mental activity, such as thinking about a teaching plan for this class. We aimed to select quotes that were mutually exclusive: if the same task happening in the same period of time was mentioned twice, then only one mention of this task was selected as a quote. As a result of this process, 183 quotes were selected for the routine task analysis.

Quotes for the routine experience analysis mean to offer contextual information about how teachers utilize their attentional resources, and how they think about and experience their tasks. Therefore, in this analysis, based on our research questions 2 and 3, we generally selected two kinds of quotes: 1. Quotes about how teachers' attention is allocated, such as how teachers perform multitasking, how teachers attend to mental tasks (e.g. reflecting on goals, making decisions), how teachers respond to 
interruptions. 2. Quotes indicating teachers' thoughts about and experiences of their routines, such as what their busiest moments in their lessons are and what situations are difficult or effortless to them. Based on these questions, we select quotes and built an initial set of categories. Each quote in this analysis is usually longer than a quote for the routine task analysis so that some contextual meaning can be kept for coders. 137 quotes were selected for routine experience analysis from the entire set of data.

Collaborative coding After selecting the quotes from the transcripts, we set up two collaborative coding sessions. In order to guarantee the reliability of the coding results, two coders were involved in these sessions: the first author (the first coder) and a researcher (the second coder) who is familiar with qualitative content analysis but not familiar with the research topic of this study. At the start of the sessions, this second coder was informed of the setup, goals and research questions of the study.

The two analyses were conducted in separate coding sessions, each of which used an identical process:

(1) The quotes (183 in routine task analysis and 137 in routine experience analysis) were divided equally over the two coders. The selection for each coder included quote from different interviews or group sessions (quotes for routine task analysis did not cover group sessions) and from different participants.

(2) Each coder read his/her quotes to get first impressions of their content. Following, each coder individually created an initial categorization for their set of quotes.

(3) Subsequently, the two coders presented their initial coding results to each other and discussed these to come to a shared categorization of quotes. As a result of these discussions, they reached an agreement on a combined set of categories.

\section{Results and discussion}

After the routine task analysis, a categorization of quotes from SRIs emerged in which teachers' mundane tasks were classified into five main categories, showing us an overview of what tasks teachers do as part of their everyday routines (research question 1). An emerged categorization of quotes selected from both SRIs and group sessions for routine experience analysis revealed rich and vivid contextual information encompassing how teachers allocate their attention during their everyday routines (research question 2), and how teachers experience their everyday routines (research question 3). In this section, the results of the two analyses will separately be presented and discussed.

\subsection{Routine tasks analysis}

The purpose of this analysis is to gain an overview of teachers' everyday tasks and an impression of teachers' classroom routines before we discuss how they allocate their attention into their tasks and how they experience their routines. Resulting from the process of collaborative coding of 183 quotes, which described teachers' tasks reported in Stimulated Recall Interviews, five main categories of teachers' routine tasks emerged (see Table 3 for detailed information and exemplar quotes of each category). Since the 


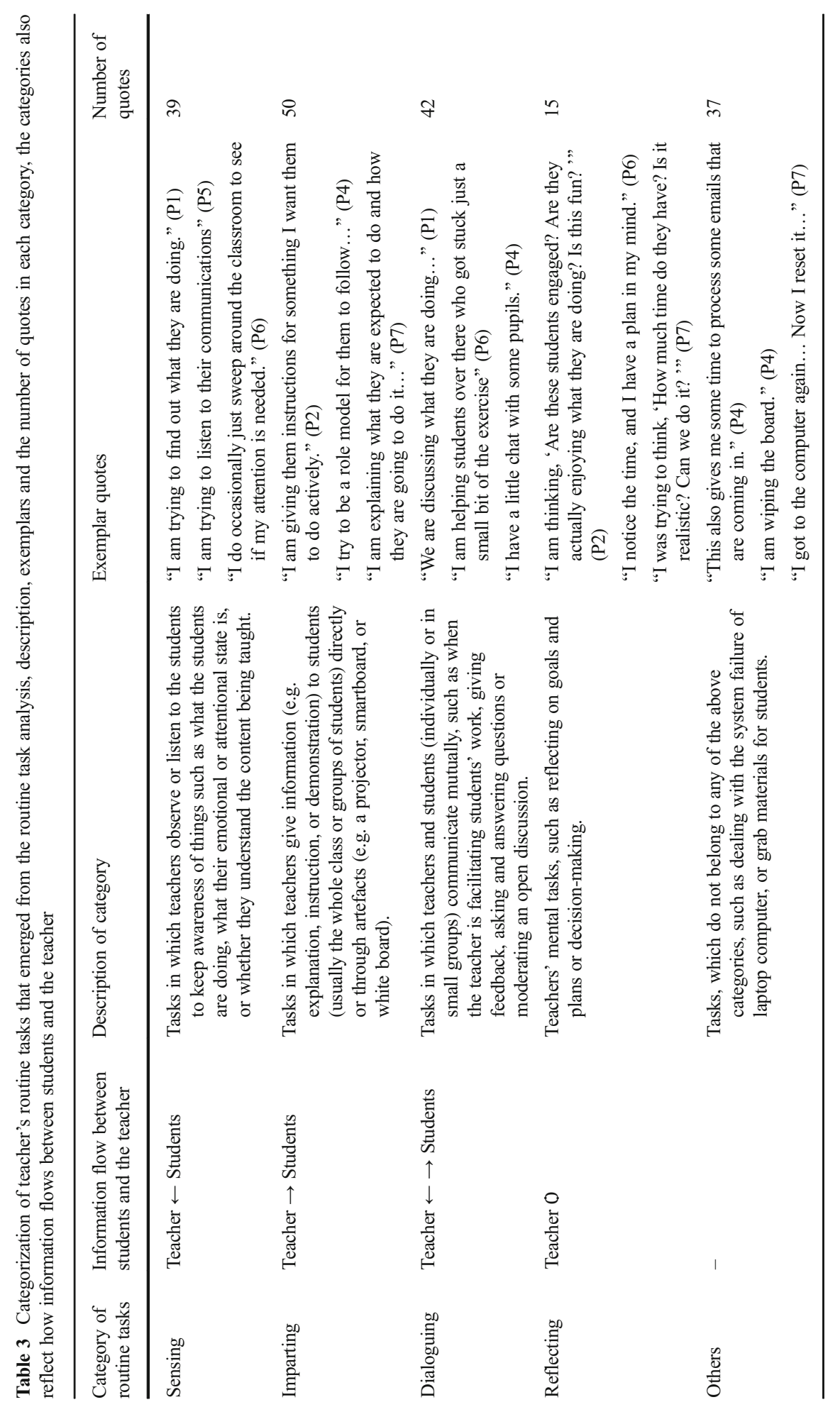




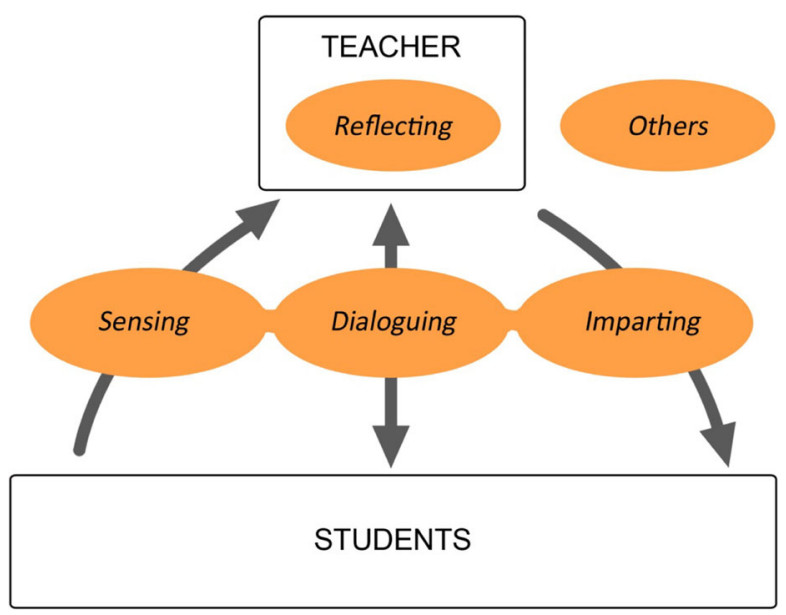

Fig. 4 An overview of the categorization of teachers' daily tasks emerged in routine task analysis. The arrows indicate the information flow between students and the teacher

large majority of tasks involved communication between students and teachers, the categorization also describes different ways of information flow between teacher and students, presented in Table 3 and Fig. 4.

The categories sensing, dialoguing, and imparting make up the majority of tasks found in the routine task analysis (131 out of 183 quotes). These categories describe communicative tasks, most of which reflect the nature of pedagogical activity: the communication between teacher and students. The quotes in these three categories reveal that this communication happens at multiple levels (see Fig. 5). Tasks belonging to categories of sensing and imparting are mostly focused on communicating with students at class-level, or large-group-level. For example, when teacher is explaining new knowledge to students (imparting), he or she usually treats the group as a whole. The teacher may try to assess an overall student reaction (sensing) and adjust his or her way of explaining accordingly, rather than putting attention on particular students too much. On the other hand, when performing tasks belonging to the category dialoguing, for example when helping a student or a small group of students, the teacher communicates with student in an individual-level or small-group-level.

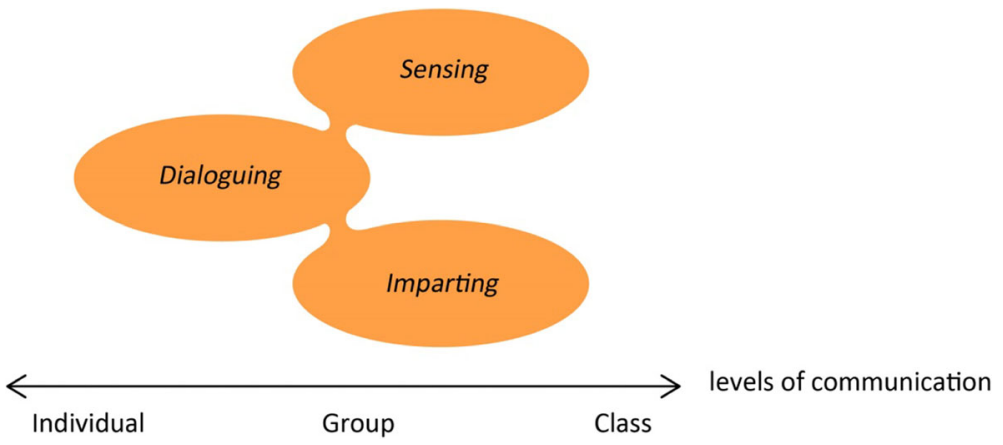

Fig. 5 Multiple levels of teachers' communicative tasks with students 
In classroom situation, tasks of sensing, dialoguing and imparting do not have clear boundaries between each other. And the communication levels of them are not absolute. They intertwine to each other to compose pedagogical activities. For example, when lecturing to students (Imparting), a teacher may also ask a question to an individual student and give him or her feedback (dialoguing). Or when a teacher is helping a small group of students (dialoguing), he or she may also try to listen to other students to keep an overview of what students are doing (sensing).

In this analysis, teachers' daily tasks in classrooms were classified into five categories (sensing, imparting, dialoguing, reflecting, and others), which gives us an overview on what tasks teachers do as part of their everyday routines. The results also have shown that the majority of teachers' routine tasks (sensing, imparting, and dialoguing) involves multilevel communication between the teacher and the students.

\subsection{Routine experience analysis}

For the routine experience analysis - analysis of how teachers allocate their attention while working and how they experience their everyday routines - we selected quotes from both the stimulated recall interviews and group sessions. Most of the 137 selected quotes for this analysis are longer than quotes selected for the routine task analysis in order to preserve their contextual meaning for coders. As a result, some of these quotes provide multi-facet insights. In this analysis, we therefore placed some of the quotes into more than one theme or category. The analysis resulted in two main themes of quotes, corresponding to two of our research questions: 2 . How do teachers allocate their attention during their everyday routines? 3. How do teachers experience their everyday routines? In each theme, there are several dominant categories revealing contextual information of different aspects of teachers' routines, and we will introduce and discuss these categories here one by one. The quotes not belonging to any of these categories have been sorted into categories called others ( 4 quotes in the theme 1 and 8 quotes in the theme 2) in both themes, which are not going to be discussed. See Table 4 for a detailed overview of the categorization.

\subsubsection{Theme 1: How do teachers allocate their attention during their everyday routines?}

Quotes in the first theme provide insights into how teachers allocate attention while working. As shown in the Table 4, three dominant categories emerged from the analysis: multitasking, interruptions, and reflective tasks.

\section{Category 1: Multitasking}

—"While you're doing a lesson, you're constantly trying to perceive..." (P4 in the group session).

Twenty-five quotes describing situations in which teachers do more than one tasks at the same time are sorted into this category. While analyzing these quotes, we found that 18 of them describe an example in which a task is performed together with a sensing task such as listening to or observing students. We call them ' $X+$ Sensing tasks' (see Table 4). For example, one of our participants reported that when reading texts to 
Table 4 Categorization emerged from routine experience analysis, with number of quotes for each (sub-/ further sub-) category indicated in the parentheses

\begin{tabular}{lll}
\hline Category & Sub-category & Further sub-category \\
\hline $\begin{array}{l}\text { Theme 1: How do teachers allocate their attention during their everyday routines? } \\
\text { Multitasking (25) }\end{array}$ & X + Sensing tasks (18) & Sensing by hearing (7) \\
& & Sensing by watching (6) \\
& Other multitasking situations (7) & Unclear (5) \\
Interruptions (23) & External interruptions (18) & Direct interrupting events (9) \\
& Self-interruptions (5) & Indirect interrupting events (9) \\
Reflective Tasks (27) & Multiple (sub-) goals (17) & Long-term goals (3) \\
& Adjusting plans (10) & Short-term goals (14) \\
Others (4) & Beginnings and transitions (18) & Beginnings of lessons (12) \\
Theme 2: How do teachers experience their everyday routines? & Beginnings of class activities (6) \\
Busiest Moments (21) & Other busiest moments (3) & \\
& Becoming easier (17) & \\
Effortless or difficult (47) & Attending to individuals (13) & \\
& Various opinions (17) & \\
Others (8) & & \\
\hline
\end{tabular}

students, "I suppose half of my brain is on the words I'm reading [...] and half of me is checking if they are following" (P2 in the SRI). In another example, a teacher said, "when I am writing on the board, I try to listen to what they (students) are saying" (P5 in the group session). We already found in routine task analysis that sensing students is a large classification among all the teacher tasks (see Table 3), and here it is shown that sensing is the most common side task of teachers' multitasking behaviors in their routines.

As shown in the Table 4, among the 18 quotes of $X+$ Sensing tasks, 7 quotes mention that teachers sense students by listening, 6 mention that teachers sense students by visual observation, and 5 quotes do not have clear information about how the teacher senses students. It may indicate that auditory perception is as a common way as visual perception for teachers to sense students when they are performing multitasking, especially when their visual perception is needed to perform the other task, for example, writing on the board, looking at the screen, or talking to other students. This is in accordance with results of related research, which found that awareness of peripheral information is mostly gained through auditory perception in everyday life (Bakker et al. 2011).

Quotes in the sub-category $X+$ Sensing tasks furthermore reveal various purposes of sensing students while teaching. For example, when a teacher is giving a lecture or demonstration to students, he or she may want to know if 
students are paying attention, if they understand what he or she is talking about, or if what has been written on the board is clear enough for students to read. When a teacher is using a computer, he or she may occasionally 'sweep around the classroom' (P6 in the group session) to see if students are doing their work or if there is any student who needs help. Even if a teacher is helping individual students, he or she may listen to other students nearby, "trying to sense what the other students are doing" (P6 in the group session), or "if they possibly have the same problems" (P5 in the group session). And sometimes, a teacher allocates his or her attention to students while doing something, just "to keep an overview of what's happening" (P6 in the group session) in the classroom.

Since $X+$ Sensing tasks show a dominant proportion among the examples of multitasking, the remaining quotes are sorted as "Other multitasking situations" (7 quotes). This sub-category contains examples in which a sensing task is not involved. For example, a teacher was "greeting students coming in, also starting up the computer" (P6 in group session) at the beginning of the class.

In this category, we found that sensing students is a very common side task in teachers' everyday routines. Teachers also indicate that it is crucial for them. "While you're doing a lesson, you're constantly trying to perceive or listen to the students." (P4 in the group session) "Whatever I'm doing, I'm trying to figure out what students are thinking..." (P5 in the group session).

\section{Category 2: Interruptions}

— "There are a lot of decisions to make." (P5 in the group session).

When performing a certain task, such as lecturing, facilitating students' group work, or walking around the classroom to oversee students working, a teacher also regularly confronts different interruptions, after which task switching might occur. 23 quotes in this category describe examples of how teachers deal with interruptions in their routines. There are mainly two types of interruptions: external interruptions (18 quotes) which are caused by students or technologies, and self-interruptions (5 quotes) which are initiated by teachers themselves (see Table 4). We found that most of the external interruptions are caused by students (16 out of 18 quotes). Others are caused by technologies such as social network applications (2 quotes). And five quotes from the sub-category self-interruptions show us that teachers tend to initiate selfinterruptions to perform secondary or supportive tasks including interaction with technologies when their workload is low.

As shown in the Table 4, we found that there are two kinds of events causing external interruptions: direct interrupting events (9 quotes) and indirect interrupting events (9 quotes). Direct interrupting events refer to situations in which the interruptions directly request a teacher's attention. For example, students raise their hands to ask questions while the teacher is lecturing; or when the teacher is helping a group of students, a student from another group come to the teacher asking for help. In situations of direct interrupting events, teachers have to react to the interrupting events immediately, by either helping the student(s) directly or indicating that the student(s) will be attended to later. As a consequence, the current task of the teacher has to be paused while the teacher has to react to the events. When discussing the situation that the students have questions while the teacher is doing something else, P4 for 
example indicated, "you have to decide on 'which will I do?' 'Will I listen to the students first and then finish the other tasks?"'. Even if the teacher decides to attend to the interrupting event later, a small task interruption occurs when informing students that their requests will be dealt with later. However, this can be done in a quite tacit manner, for example with an 'automatic nod' to the students (P4 in the group session).

Nine quotes describe indirect interrupting events (see Table 4), situations which are not directly intended to request the teacher's reaction immediately, for example, when a teacher perceives that a student is distracted, falling behind the schedule of the lesson, or saying something interesting in the group discussion, or when the teachers notice that there are new messages from his or her social network. Unlike direct interrupting events, indirect interrupting events do not necessarily require the teacher to stop his or her current activity. In other word, these events are more deferrable and ignorable than direct interrupting events. If they get deferred by the teacher, they may become a selfinterruption which will initiated by the teacher later. For example, P4 reported a moment during his lesson in the SRI when he noticed that one of students was playing with his phone. P4 decided to carry on his activity and deal with it later, "I just let it be until I had some time talk to him." Teachers may also decide to react to the indirect interrupting events immediately. For example, P6 reported in the SRI that when he was helping a few students in his class, he noticed that some other students were getting distracted. So he decided to take action immediately, "So for me that is a cue: okay, now I have to go over there and check..." Interestingly, two quotes from indirect interrupting events describe interruptions caused by WhatsApp messages from colleagues (P5 in the group session) or friends (P6 in the group session) during their lesson. P5 described an example that during her lesson she looked at her phone to check her agenda, "And then I notice that there are a lot of WhatsApp notifications from my colleagues asking me to do things, then there's another information load coming" Both P5 and P6 thought receiving such messages while working was 'quite intrusive' (P6 in the group session) to them.

In the sub-category self-interruptions (see Table 4), there are five quotes showing us that low-workload periods, usually when students are working independently with the teacher observing, are prone to initiate self-interruptions to carry out secondary or supportive tasks. These tasks can include interacting with technologies, such as answering emails from colleagues (P4 in the group session), using administration software (P3 in the SRI), or checking the laptop (P7 in the SRI). At low-workload moments, teachers decide to switch their attention from students to secondary or supportive tasks since "right now they (students) do not need my attention" (P7 in the SRI), "that could be the moment I could do something else" (P3 in the group session).

In this category, we found that while teaching, teachers have to regularly deal with interrupting events mostly caused by students, and sometimes by technologies. Being interrupted, teachers have to make quick decisions on whether, when and how to react to those interruptions. As stated by P5, "there're a lot of decisions to make." Some of the interruptions need immediate reactions and some of the interruptions can be deferred to become self-initiated interruptions later. Teachers tend to initiate selfinterruptions to interact with technologies during low-workload periods when they do not have to pay much attention to students. 


\section{Category 3: Reflective Tasks}

- "My mind is doing a lot of things at the same time." (P6 in the group session).

As Table 4 shows, 27 quotes in this category describe what reflective tasks teachers attend to when they are teaching. We found that teachers may have multiple goals or sub-goals to pursuit in a pedagogical activity, and they need to occasionally check if (sub-) goals are being fulfilled (17 quotes). Additionally we found that teachers occasionally think about if they need to adjust their lesson plan according to the condition of the class (10 quotes).

In the sub-category multiple (sub-) goals, 3 quotes describe long-term goals (see Table 4), which always direct the teacher's behavior while he or she is working. For example, P6 indicated in the group session that there were some general goals in his mind: "I try to encourage students, make them gain knowledge, give them some change inside". P2 indicated in the group session that she aimed to give students "a feeling of success" while teaching. These long-term goals, as P2 felt, are "sitting away in some part of your brain all the time..." And teachers occasionally think about how they can achieve those goals. And that, for P2, felt like "a kind of multitasking". Besides those long-term general goals, there are also some more concrete (sub-) goals for teachers to pursuit in different classroom activities, which is categorized in further sub-category short-term goals (14 quotes). Given the complex nature of pedagogical work, an activity of a teacher may have multiple sub-goals, which the teacher has to check in his or her mind every now and then while doing the specific work. For example, P3 (in the group session) reported that while lecturing, besides attending to things he is talking about, he was also thinking about "Are they (students) reading? Are they paying attention? How am I doing? Am I clear?" in his mind.

Teaching is dynamic and unpredictable. The sub-category adjusting plans (see Table 4) includes quotes describing that every now and then in the classrooms, teachers have to decide whether to readjust their plans or ways of teaching according to the conditions of the class at the moment (10 quotes). As P4 described in the group session that to him a plan for a lesson is just like "some recipe in your head", and he has to "keep track of where you were in your recipe..." and this is usually done by the teacher perceiving the conditions of the class by experience. Once the teacher finds that students respond or behave differently than expected, he or she might adjust the plan (for example, the teacher quickens the pace of teaching or slows it down) to a certain extend to fit the current situations. P2 (in the group session) thought that as an experienced teacher, "you can assess the atmosphere" of the class, and "possibly to change a plan to fit what the atmosphere is."

In this category, we found that while teaching, teachers may occasionally focus their attention on checking if they kept on fulfilling their multiple (sub-) goals, and also think about whether to adjust their teaching plan to better fit to the current situations of the class. These reflective tasks may give a teacher a feeling that "my mind is doing a lot of things at the same time" (P6 in the group session).

\subsubsection{Theme 2: How do teachers experience their everyday routines?}

This theme collects quotes describing teachers' feelings and experiences of their routines. There are two dominant categories: the first describing the busiest moments 
that teachers find during their lessons, and the second describing situations which teachers find effortless or difficult while working.

\section{Category 1: Busiest Moments}

— The beginning of the lesson is the busiest time." (P2 in the group session).

21 quotes in this category describe the moments teachers think are busiest in their lesson. As it shows in the Table 4, there are 18 quotes in the sub-category Beginnings and transitions indicating that teachers find the beginnings of and transitions between lessons and class activities are the busiest moments in their routines. There are also some other reasons that may cause teachers' feeling of busyness from the sub-category other busiest moments (3 quotes).

All the participants agreed that the beginning of a lesson is the busiest moment for them (12 quotes in the further sub-category beginnings of lessons). On one hand, at the beginning of a lesson a teacher may have a lot of 'physical stuff' (P4 in the group session), or 'mechanical things' (P2 in the group session) to do, such as starting up the computer to prepare the slides or take attendance of students, opening the textbook at the right page, collecting homework, writing down the planning of the lesson on the whiteboard or moving things from place to place. Meanwhile, the teacher also has to interact with students coming into the classroom: greeting students, having casual conversations, keeping an overview of what students are doing, and asking them to prepare for the lesson. Additionally, the beginning of a lesson can also be considered as a transition between two lessons during which students from the previous lesson may still have questions that need to be answered while students for the next lesson are coming into the classroom at the same time. All situations described above make teachers feel that "there are lots of things happening at the same time." (P6 in the group session) Apart from the beginning of a lesson, or transition between two lessons, the participants indicated that the beginnings of and transitions between different teaching activities also lead busy moments ( 6 quotes in the further sub-category beginnings of class activities). For example, P3 told us in the group session that he felt the moments when he switched from lecturing to overseeing students working on their own are very busy for him. At such moments he may have to describe to students what they have to do, answer questions from students, and help some of the students who have difficulties.

In the sub-category other busiest moments, three quotes describe busiest moments other than beginnings or transitions. For example, P5 (in the group session) found the moment in which her students were doing practical experiments very busy, because there might be some students doing wrong things at the same time and she needs to correct them all. A sudden arising of multiple questions from students at some points is also considered by P4 (in the group session) as a busy moment.

Teachers indicated that after the busyness at the start of lessons or lesson-periods, their routines usually get less busy ( 3 quotes belonging to the sub-category Beginnings and transitions from P1, P2 and P6 in the group sessions). One participant experienced that, "The beginning is the hard thing. And once you've got people doing, you've got the thing going, and it's a bit like starting up a machine. Once you got it started, it's going to run itself" (P2 in the group session). P1 (in the group session) said that, "In the beginning, I think, It's hard..." and she had to allocate her attention to students who needed different helps, but once started, students will get to a 
point where they do not need much attention from the teacher, and she thought "then that becomes much easier".

This category shows us that the start of, and transitions between, lessons and class activities are the busiest moments considered by teachers. Multiple tasks to fulfill make their workload relatively high at these moments. But after these moments, teaching may become less busy for them since students may get to a more autonomous learning state, and the intensity of tasks may get reduced.

\section{Category 2: Effortless or Difficult}

- "Becomes easier." (P6 in the group session).

It is shown in Table 4 that 47 quotes in this category describe classroom situations that teachers see as difficult parts of their routines, and situations they see as effortless parts of their routines. In the sub-category becoming easier, 17 quotes reveal that as a teacher gets more experienced in teaching, some of the tasks will get more effortless or even automatic for him or her. The sub-category attending to individuals (13 quotes) indicates that teachers think it is difficult to attend to every individual student in their lessons, given the current number of students they have for each class. The 17 quotes remaining compose the sub-category various opinions which reflects various opinions from teachers about their effortless or difficult situations.

The sub-category various opinions shows us that different teachers have different opinions about which parts of their routines they find difficult or effortless, and some of the views are even opposite to each other. For example, one of our participants, who had one year of teaching experience, thought that while giving a lecture, paying attention to students' behavior is "a little bit difficult" (P3 in the group session). However, another participant who has been teaching for 6 years thought that "While I'm explaining or demonstrating things on the board, I can easily observe what's happening in the class." (P6 in the group session).

Participants reasoned that these differences depend on how experienced a teacher is (i.e. how long he or she has been teaching), which is shown by the sub-category Becoming easier (17 quotes). Quotes in this sub-category show situations that have become easier for teachers after years of teaching. For example, P6 (in the group session) indicated that, "I think when teaching a longer time, (you) already have quite some good ideas why people get stuck..." When talking about the multiple tasks that need to be done at the start of the lesson, P4 (in the group session) commented that, "After you get more experienced, you kind of do those things simultaneously..." P4 added that, at beginning of the lesson, although interaction with students may still take a lot of time, finishing the 'physical' setup (such as starting up computer and smartboard and moving things from place to place) is getting 'easier' ("it takes less time, I think, and not much attention" (P4 in the group session)). Similarly, P3 (in the group session) thought that "some parts of your lesson will become [...] automated". Therefore, "you can easily pay attention to something else".

As concluded earlier, our participants indicated that they always try to be aware of what every student is doing. However, the sub-category attending to individuals (13 quotes) shows that a bottleneck of a teacher's attention seems to appear when higher numbers of students are involved. P6 indicated (in the group session) that it is doable for him to remain aware of what everyone is doing in class of 15 students, while most 
of time, there are 25 or more students. P2 thought that if there are 30 students, "it's easier for students to slip through the cracks" (P2 in the SRI). P7 indicated that it is possible for her to be aware of what other students are doing while helping a group of students in a small class, but "if there were 20 students, it gets more difficult" (P7 in the SRI). P5 (in the SRI) thought it is 'hectic' to attend to all the students in a class of 29 students.

There are more situations described in the sub-category various opinions, showing that teachers have diverse opinions on which tasks of theirs are difficult or effortless. For example, P1 and P3 mentioned that to deal with students with negative attitudes are quite effortful. P1 (in the group session) said that "when the attitude of students is poor, that burdens me." For another example, P5 (in the group session) told us that she had difficulty to type something on the computer and meanwhile answer a question from a student, while she could easily hear what students are talking about and write things on the whiteboard simultaneously.

In this category we found that teachers' opinions on whether their tasks are effortless or difficult can be quite different depending on how many years they have been teaching. As a teacher gets more experienced in teaching, he or she may get better at doing things simultaneously: some tasks will become 'automated', which imposes a lower workload. Additionally, we found that most participants thought that, even though remaining aware of all students' current state and progress is important, it is difficult to realize this in classes consisting of 20 or more students.

\subsection{Limitations}

Although the study has yielded rich and vivid contextual information needed to answer our research questions, there naturally are also a number of limitations to the research conducted. Because of the choice to conduct an in-depth qualitative study using contextmapping methodology, in line with the qualitative aims of our research, the number of involved participants is relatively low. By involving seven participants, though diverse in gender, age, teaching experience and teaching subjects, the study could likely not cover all possible teaching scenarios, resulting in a potential bias. A bias could furthermore be caused by the fact that in the sensitization phase, we conducted SRIs based on the recording of one single lesson of each participant. More diverse routine activities might have been covered when recording multiple lessons of one teacher and when involving a larger participant group. Another limitation of this study is that during the research, both P3 and P7 were not able to participate in the complete process of the study (P3 was not able to participate in the SRI and P7 missed the group session). While the mentioned limitations indicate suggestions for improvement in study design for future studies with similar aims, we also recognize these limitations as inherent to the in-depth and qualitative approach chosen, which we believe to be essential given the qualitative nature of the research questions.

\section{Design opportunities}

The starting point of this study is the assumption that secondary school teachers have quite busy everyday routines in their classrooms. Based on this assumption, we believe 
that employing the principles of peripheral interaction (Bakker et al. 2014) which concerns reducing the attentional resources required from users is meaningful to design and development of classroom technologies. Therefore, from a perspective of design, the contextmapping study presented in this paper was conducted to gain a better understanding on secondary school teachers' existing routines. The study results with rich and vivid contextual information reflect the busy and dynamic nature of everyday routines of secondary school teachers, which has verified our basic assumption and thus has supported that teachers' routines in classrooms are a very promising context for deploying peripheral interaction. Undoubtedly, classroom technologies which do not require much focused attention to interact with will disburden teachers who are already quite busy, and enable them to focus beyond the technologies thus to have more attentional resources for students. Based on findings from the analyses, here we identify several design opportunities to inform designers and developers of classroom technologies.

\subsection{Design opportunity 1: Disburdening teachers' eyes and ears}

From our two analyses we concluded that sensing (with the purpose of remaining aware of students' activities, attention levels, or emotional states) is the most common side tasks in teachers' everyday routines. It seems that whatever teachers are doing, they always try to keep aware of students' state. As a result, teachers' visual and auditory attention is frequently occupied by sensing students while they are teaching. According to Multiple Resource Theory (MRT) (Wickens 2002), if two tasks require the same modality or cognitive resource, interference will occur so that it may not be possible to be performed in parallel. Therefore, on the one hand, developers and designers might try to reduce the amount of focused visual or auditory attention required from teachers to interact with the technologies, for example, by means of ambient display (Mankoff et al. 2003), or ambient soundscape (Butz and Jung 2005). On the other hand, developers and designers might explore alternative modalities for the interaction between teachers and technologies. Haptic perception (e.g., (Williams and Michelitsch 2003)), proprioception (sense of the positions and postures of our own body and limbs, see, for example, (Lopes et al. 2015)) and other modalities of perception may also be utilized to support teachers' technology-related tasks, making the tasks easier to be performed in quasi parallel with other tasks. For example, imagine a bracelet that can work as a timer and give haptic feedback to the teacher. If the teacher sets the bracelet for a 20-min period for students to do some exercises, while he or she is walking around and helping students, the bracelet will perform a subtle vibration pattern every five minutes to help the teacher remain aware of how much time has passed in this period, before it will give a stronger feedback to indicate the time is up. By using haptic perception to keep general time awareness in classroom activities, the teacher does not have to visually focus on a timer application on the computer.

\subsection{Design opportunity 2: Design for interruptibility}

As we found in our study, while working, teachers have to deal with various interrupting events mostly caused by students, and sometimes also by technologies. 
We also found that teachers prefer to initiate self-interruptions to interact with the technologies (for example, emails, or administration software) when they are in lowworkload conditions. To fit in these highly dynamic everyday routines, technologysupported tasks might be designed to be flexible enough, so that they can be potentially interrupted by, switched with other tasks, and deferred by teachers. Of course also they should be resumed effortlessly without causing much extra mental load. To explain this, we can take one of teacher routine tasks, recording attendance, as an example. A current way for a teacher to fulfill this task is to use school administration software on his or her laptop. The teacher has to fill attendance information into a digital name list of all the students and then submit it. If the teacher gets interrupted by another task and has to leave his or her desk, after the interrupting task, he or she needs to go back to the desk and scan through the list on the screen to find out the point where he or she just stopped to resume the task. To make this task more interruptible, a possible concept design may be a mobile application for attendance recording. When the application is focused, one student's name will be displayed on the screen each time, and only after inputting attendance of this student, it will be replaced by the name of another student, until all the information is completed. In this way, the whole task is divided into small fragments, and teachers can choose to finish several fragments at a small time slot when they are not busy. Once interrupted, teachers can resume this task more effortlessly. Moreover, when designing technology-supported tasks for teachers, we may try to avoid these technologies to cause direct interrupting events to teachers when their workload is already relatively high (such as at the beginnings of and transitions between lessons and activities at which they feel considerably busy as we found). To achieve this, classroom technology might be designed to be activity-aware (for example, the system knows which activity or situation the user is in currently) and useradaptive (for example, the system knows how much mental load the user has, and thus determines whether or not to interrupt the user).

\subsection{Design opportunity 3: More information for teachers}

In our study we found that teachers have multiple goals and sub-goals to pursuit when they are in different activities, and they have to regularly check if they keep achieving these (sub-) goals. Additionally, they frequently assess whether they should adjust their plans or strategies of teaching in order to fulfill their (sub-) goals, based on the current context in the classrooms, such as students' feedback, performance, or attention level. This finding reflects how dynamic classroom activities are for teachers, and explains why sensing tasks are crucial to them. Therefore, it will be meaningful for teachers that more relevant information, especially that cannot be directly or easily perceived by sensing tasks (e.g. attention level, emotional state of each students, student performance in certain exercises,), can be presented to them in real-time. For example, imagine there is an ambient display system presenting in real-time information about how much time the teacher has spent on helping each student. While a teacher is teaching, he or she may sometimes notice the information, and it could support the teacher to make decisions on whether he or she should spend more time on helping a student or whether he or she should go to another student. However as we mentioned in the design opportunity 1 , such displays should be unobtrusive, unarrestive, and ignorable, so that the information could support teachers assess and adjust their teaching more efficiently 
without causing much extra cognitive load. Some of the related work we addressed before, such as studies done by Moraveji et al. (2011); Sturm et al. (2006), and van Alphen and Bakker (2015) can be seen as early explorations into this direction and have shown their potential value for teachers. We believe that there is more space to be explored in this opportunity.

\subsection{Design opportunity 4: Design for personalization}

From routine experience analysis, we concluded that teachers' experiences and feelings of their routines can be rather different. Moreover, different teachers have different capabilities of task performing. Factors such as years of teaching experience lead to this differentiation. We also found from our participants who are diverse in the subjects taught by them that teachers of different subjects have different activities in their lessons. For example, one of the most common teaching activities for an English teacher might be to read the textbook to students and explain the content, whereas a mathematics teacher, what he or she frequently does in the lessons might be demonstrating calculations on the whiteboard for students to follow. Now that teachers differ in experience, capability, activity of their daily work, it is reasonable for classroom technologies to be personalized to adapt to different preferences of teachers. For example, imagine that there is a handheld controller, which has some shortcut buttons that can help the teacher remotely activate and simply manipulate laptop-based applications displayed on the smart whiteboard. Since different teachers may have different frequently used applications, teachers may prefer to define the functions of the shortcut buttons by themselves. For example, the English teacher may want to have an online dictionary mapped to a button, while the mathematics teacher may want to have a virtual calculator for demonstrating to students. For teachers who are quick learners of using technologies, they may set more shortcut buttons than those who are not experienced in using technologies. Additionally, as the teacher gets more familiar with using the controller, he or she may define more shortcut buttons to control applications. Therefore, in order to make the technologies fit into different routines of teachers, we might try to make the classroom technologies open-ended, and enable personalization by users.

\subsection{Design opportunity 5: Support for multilevel communication}

As our routine task analysis shows, communication between students and teachers in pedagogical activities are multilevel, which means that some of the communicative tasks take place on class-level, whereas some of them take place on small-group or individual level. When doing tasks belonging to sensing or imparting, teachers usually see the entire class or a group of students as a whole. And while performing tasks belonging to dialoguing, teachers tend to address students as individuals or small groups. However, we also found that communication on individual-level is somewhat constrained because of the large numbers of students in one class: evenly divide attention to each individual student is challenging. An opportunity for classroom technologies might be to facilitate these multilevel communications in pedagogical activities, supporting teachers to manage, instruct, or help students flexibly and precisely, so that they can not only teach the class as a whole, but also easily track the 
learning of groups or individuals and correspondingly give each student specific instructions, explanations, or missions when they need. For example, as we addressed in the related work section of this paper, FireFlies (Bakker et al. 2013) enables a teacher to give simple feedback to students individually through changing the color of a student's lamp, while the teacher is overseeing students working. Another example, Subtle Stone (Alsmeyer et al. 2008) helps each student communicate his or her current emotion to the teacher by squeezing an orb. And the teacher can be aware of not only the overall emotional state of the class but also different emotions of individuals, based on which he or she could adjust teaching. These examples show us how technologies can facilitate multilevel communication in pedagogical activities, and we believe that there are more possibilities to explore.

\section{Conclusion}

In this paper, we present a qualitative study on classroom routines of secondary school teachers from an interaction-design perspective. We started from the assumption that secondary school teachers have quite busy routines in which a lot of their attentional resources need to be occupied by various daily tasks. We therefore believe that employing the principals of peripheral interaction (Bakker et al. 2014), which can reduce attentional resources required from users, is meaningful for design and development of classroom technologies. In order to design and develop technologies that can be used in the periphery of teachers' attention, and become seamless part of teachers' routines, a thorough understanding of existing routines of secondary school teachers is needed. Therefore, this paper targets on informing the designers and developers aiming to design such classroom technologies with rich and vivid contextual information on teachers' routines gained by using contextmapping (Visser et al. 2005) methodology. Results of two analyses presented in this paper address our three research questions: 1 . What tasks do teachers do as part of their everyday routines? 2. How do teachers allocate their attention during their everyday routines? 3 . How do teachers experience their everyday routines?

To address research question 1, routine task analysis has been conducted. A categorization of teachers' classroom tasks emerged from the analysis providing an overview of teachers' routine tasks. In the categorization, teachers' routine tasks are classified into five categories (sensing, imparting, dialoguing, reflecting, and others). And a multilevel feature of teachers' communicative tasks (sensing, imparting, and dialoguing) is also reflected by the analysis. To answer research question 2 and 3, we conducted routine experience analysis. The first part of the results (theme 1) shows us vivid pictures of how teachers allocate attention in their routines. We found that whatever tasks teachers are doing, they always try to also attend to students to get aware of their state. While teaching, teachers frequently confront different interrupting events externally, and they also initiate self-interruptions when their work-load is relatively low. Occasionally, teachers need to reflect on multiple (sub-) goals and teaching plans in their minds and think about whether they should adjust their teaching plans based on what they have sensed from the class. The second part of results (theme 2) of routine experience analysis shows how teachers experience their routines. We found that beginnings of, and transitions between, lessons and different teaching activities are considered as the busiest moments for teachers. And teachers feel less busy when students get to a more autonomous learning state after the 
busy starts of activities. We found that teachers' opinions on which tasks are effortless and which tasks are difficult differentiate depending on years of teaching experience. For an experienced teacher, some of the tasks may have become effortless or even automatic. Additionally, we found that allocating enough attentional resources to each individual student is considered as difficult by most of the teachers, if the number of students per class is higher than 20 .

Results of this study show us rich and vivid information about busy and dynamic routines of secondary school teachers, which verified our basic assumption. Our findings therefore support our approach of exploring peripheral interaction as a meaningful human-computer-interaction style for secondary school teachers. Based on findings from the analyses, we identified five design opportunities. We propose that classroom technologies may reduce focused visual or auditory attention required from teachers, and leverage their capabilities of peripheral perception. Teachers' tasks supported by technologies may have more flexibility to be interruptible, which means they can be interleaved with other daily tasks, or deferred by teachers, without demanding much mental effort to resume. We believe that it is meaningful for technologies to present more real-time information (such as status or performance of students) to teachers, in an unobtrusive and unarrestive manner, so that teachers can be better aided to fulfill goals and make decisions. We also suggest that classroom technologies can be open-ended and easily personalized by users to support teachers who have different routines and various preferences of using technologies. Last but not the least, we think the classroom technology may facilitate the multilevel communication between students and teachers, so that teachers can not only interact with students on the class or group level, but also have effective dialogues with individuals. These design opportunities and considerations mean to inform the design and development of classroom technologies that are to become a fluent part of teachers' everyday routines. We expect that the findings and conclusions of this paper could help designers and developers gain better insights into the context of classroom technologies, especially routines of secondary school teachers.

Acknowledgments We thank the seven secondary school teachers for participating our study despite their busy jobs. And we thank the second coder of the two analyses for nice help.

Open Access This article is distributed under the terms of the Creative Commons Attribution 4.0 International License (http://creativecommons.org/licenses/by/4.0/), which permits unrestricted use, distribution, and reproduction in any medium, provided you give appropriate credit to the original author(s) and the source, provide a link to the Creative Commons license, and indicate if changes were made.

\section{References}

Aili, C., \& Brante, G. (2007). Qualifying teacher work: Everyday work as basis for the autonomy of the teaching profession. Teachers and Teaching: theory and practice. http://www.tandfonline.com/doi/abs/10. 1080/13540600701299791. Accessed 10 November 2015

Alavi, H. S., \& Dillenbourg, P. (2012). An ambient awareness tool for supporting supervised collaborative problem solving. IEEE Transactions on Learning Technologies, 5(3), 264-274. doi:10.1109/TLT.2012.7.

Alsmeyer, M., Luckin, R., \& Good, J. (2008). Developing a novel interface for capturing self reports of affect. Proc. CHI '08, ACM Press, 2883. doi:10.1145/1358628.1358778

Antona, M., Margetis, G., Ntoa, S., Leonidis, A., Korozi, M., Paparoulis, G., \& Stephanidis, C. (2010). Ambient intelligence in the classroom: an augmented school desk. In International Conference on Applied Human Factors and Ergonomics. 
Bakker, S., van den Hoven, E., \& Eggen, B. (2011). Knowing by ear: Leveraging human attention abilities in interaction design. Journal on Multimodal User Interfaces, 5(3-4), 197-209. doi:10.1007/s12193-0110062-8.

Bakker, S., van den Hoven, E., Eggen, B., \& Overbeeke, K. (2012). Exploring peripheral interaction Design for Primary School Teachers. In Proceedings of the Sixth International Conference on Tangible, Embedded and Embodied Interaction - TEI '12, 1(212) (pp. 245-252). doi:10.1145/2148131.2148184.

Bakker, S., van den Hoven, E., \& Eggen, B. (2013). FireFlies: Physical peripheral interaction design for the everyday routine of primary school teachers. In Proceedings of Tangible and Embodied Interaction, TEI 2013, Feb 10-13, 2013, Barcelona (p. 8 pages). http://dl.acm.org/citation.cfm?id=2460634

Bakker, S., van den Hoven, E., \& Eggen, B. (2014). Peripheral interaction: Characteristics and considerations. Personal and Ubiquitous Computing, 239-254. doi:10.1007/s00779-014-0775-2.

Beauchamp, G. (2004). Teacher use of the interactive whiteboard in primary schools: Towards an effective transition framework. Technology, Pedagogy and Education, 13(3), 327-348. doi:10.1080/ 14759390400200186.

Becker, H. J. (2000). Findings from the teaching, learning, and computing survey: Is Larry Cuban right? Education Policy Analysis Archives, 8(51), 1-31. doi:10.14507/epaa.v8n51.2000.

Bodén, M., Dekker, A., Viller, S., \& Matthews, B. (2013). Augmenting play and learning in the primary classroom. In Proceedings of the 12th International Conference on Interaction Design and Children IDC '13 (pp. 228-236). New York, New York, USA: ACM Press. doi:10.1145/2485760.2485767.

Brante, G. (2009). Multitasking and synchronous work: Complexities in teacher work. Teaching and Teacher Education, 25(3), 430-436. doi:10.1016/j.tate.2008.09.015.

Brummelhuis, A. ten, Kramer, M., Post, P., \& Zintel, C. (2015). Vier in balans-monitor 2015. Kennisnet. https://www.kennisnet.nl/fileadmin/kennisnet/publicatie/vierinbalans/Vier_in_balans_monitor_2015.pdf

Butz, A., \& Jung, R. (2005). Seamless user notification in ambient soundscapes. In Proceedings of the 10th international conference on Intelligent user interfaces - IUI '05 (p. 320). New York: ACM Press. doi:10. 1145/1040830.1040914

Charoenying, T. (2008). Accountable game designs for classroom learning. In Proceedings of the 7th international conference on Interaction design and children - IDC '08 (p. 1). New York: ACM Press. doi: $10.1145 / 1463689.1463703$

Cuban, L., Kirkpatrick, H., \& Peck, C. (2001). High access and low use of Technologies in High School Classrooms: Explaining an apparent paradox. American Educational Research Journal, 38(4), 813-834. doi:10.3102/00028312038004813.

da Silva, V. C., Santos de Goes Jr., E., da Hora França, M. \& Ambrósio, P. E. (2011). Words Game in an Educational Context: Augmented Reality Aplication. In 2011 XIII Symposium on Virtual Reality (pp. 128-133). IEEE. doi:10.1109/SVR.2011.38

Dean, J. (2013). Making Habits, Breaking Habits: Why We Do Things, Why We Don't, and How to Make Any Change Stick. Boston: Da Capo Press.

Dempsey, N. P. (2010). Stimulated recall interviews in ethnography. Qualitative Sociology, 33(3), 349-367. doi:10.1007/s11133-010-9157-x.

Doyle, W. (1977). Learning the Classroom Environment: An Ecological Analysis of Induction Into Teaching. http://eric.ed.gov/?id=ED135782. Accessed 10 November 2015

Golombek, P. R. (1998). A study of language teachers' personal practical knowledge. TESOL Quarterly, 32(3), 447-464. doi:10.2307/3588117.

Greiffenhagen, C. (2011). Making rounds: The routine work of the teacher during collaborative learning with computers. International Journal of Computer-Supported Collaborative Learning, 7(1), 11-42. doi:10. 1007/s11412-011-9134-8.

Horn, M. S., \& Jacob, R. J. K. (2007). Designing tangible programming languages for classroom use. In Proceedings of the 1st international conference on Tangible and embedded interaction - TEI '07 (p. 159). New York: ACM Press. doi:10.1145/1226969.1227003

Hsieh, H.-F., \& Shannon, S. E. (2005). Three approaches to qualitative content analysis. Qualitative Health Research, 15(9), 1277-1288. doi:10.1177/1049732305276687.

Lamberty, K. K., Froiland, K., Biatek, J., \& Adams, S. (2010). Encouraging awareness of peers' learning activities using large displays in the periphery. In Proceedings of the 28th of the international conference extended abstracts on Human factors in computing systems - CHI EA '10 (p. 3655). New York: ACM Press. doi:10.1145/1753846.1754034

Lopes, P., Ion, A., Mueller, W., Hoffmann, D., Jonell, P., \& Baudisch, P. (2015). Proprioceptive interaction. In Proceedings of the 33rd Annual ACM Conference on Human Factors in Computing Systems - CHI '15 (pp. 939-948). New York, New York, USA: ACM Press. doi:10.1145/2702123.2702461. 
Mankoff, J., Dey, A. K., Hsieh, G., Kientz, J., Lederer, S., \& Ames, M. (2003). Heuristic evaluation of ambient displays. In Proceedings of the conference on Human factors in computing systems - CHI '03 (p. 169). New York: ACM Press. doi:10.1145/642611.642642

Moraveji, N., Morris, M., Morris, D., Czerwinski, M., \& Henry Riche, N. (2011). ClassSearch: Facilitating the Development of Web Search Skills Through Social Learning. In Proceedings of the SIGCHI Conference on Human Factors in Computing Systems (pp. 1797-1806). doi:10.1145/1978942.1979203

Offermans, S. A. M., van Essen, H. A., \& Eggen, J. H. (2014). User interaction with everyday lighting systems. Personal and Ubiquitous Computing, 18(8), 2035-2055. doi:10.1007/s00779-014-0759-2.

Pousman, Z., \& Stasko, J. (2006). A taxonomy of ambient information systems: four patterns of design. Proceedings of the working conference on Advanced visual interfaces, 67-74. doi:10.1145/1133265. 1133277

Prieto Santos, L. P., Sharma, K., Wen, Y., \& Dillenbourg, P. (2015). The burden of facilitating collaboration: Towards estimation of teacher orchestration load using eye-tracking measures. Exploring the Material Conditions of Learning: The Computer Supported Collaborative Learning (CSCL) Conference 2015, 1, 212-219. http://infoscience.epfl.ch/record/209187. Accessed 10 November 2015

Ruthven, K., Hennessy, S., \& Brindley, S. (2004). Teacher representations of the successful use of computerbased tools and resources in secondary-school English, mathematics and science. Teaching and Teacher Education, 20(3), 259-275. doi:10.1016/j.tate.2004.02.002.

Shaer, O. (2009). Tangible user interfaces: Past, present, and future directions. Foundations and Trends ${ }^{\circledR}$ in Human-Computer Interaction, 3(1-2), 1-137. doi:10.1561/1100000026.

Stanton, D., Pridmore, T., Bayon, V., Neale, H., Ghali, A., Benford, S., et al. (2001). Classroom collaboration in the design of tangible interfaces for storytelling. In Proceedings of the SIGCHI conference on Human factors in computing systems - CHI'01 (pp. 482-489). New York, New York, USA: ACM Press. doi:10. $1145 / 365024.365322$.

Sturm, J., Iqbal, R., \& Terken, J. (2006). Development of peripheral feedback to support lectures. In S. Renals \& S. Bengio (Eds.), Machine learning for multimodal interaction (pp. 138-149). Berlin: Springer. doi:10. $1007 / 11677482$.

Sylla, C. (2013). Designing a tangible interface for collaborative storytelling to access "embodiment" and meaning making. In Proceedings of the 12th International Conference on Interaction Design and Children - IDC"13 (p. 651). New York: ACM Press. doi:10.1145/2485760.2485881

Tolmie, P., Pycock, J., Diggins, T., MacLean, A., \& Karsenty, A. (2002). Unremarkable computing. Computer-Human Interaction (CHI) Conference 2002, 1(1), 399-406. doi:10.1145/503447.503448.

Urhahne, D., Schanze, S., Bell, T., Mansfield, A., \& Holmes, J. (2010). Role of the teacher in computersupported collaborative inquiry learning. International Journal of Science Education, 32(2), 221-243. doi:10.1080/09500690802516967.

van Alphen, E., \& Bakker, S. (2015). Lernanto: An Ambient Display to Support Differentiated Instruction. In 11th International Conference on Computer Supported Collaborative Learning (pp. 759-760).

Visser, F. S., Stappers, P. J., van der Lugt, R., \& Sanders, E. B.-N. (2005). Contextmapping: Experiences from practice. CoDesign, 1(January 2015), 119-149. doi:10.1080/15710880500135987.

Weiser, M., \& Brown, J. S. (1997). The Coming Age of Calm Technology. In Beyond Calculation (pp. 75-85). doi:10.1007/978-1-4612-0685-9 6

Wickens, C. D. (2002). Multiple resources and performance prediction. Theoretical Issues in Ergonomics Science, 3(2), 159-177. doi:10.1080/14639220210123806.

Williams, J., \& Michelitsch, G. (2003). Designing effective haptic interaction. In CHI '’03 extended abstracts on Human factors in computing systems - CHI '03 (p. 856). New York: ACM Press. doi:10.1145/765891. 766033

Wood, W., Quinn, J. M., \& Kashy, D. a. (2002). Habits in everyday life: Thought, emotion, and action. Journal of Personality and Social Psychology, 83(6), 1281-1297. doi:10.1037/0022-3514.83.6.1281.

Yinger, R. (2009). Routines in teacher planning. Theory Into Practice. http://www.tandfonline.com/doi/abs/10. 1080/13540600701299791. Accessed 10 November 2015

Zhang, Z., Shrubsole, P., \& Janse, M. (2010). Learning environmental factors through playful interaction. In Proceedings of the 9th International Conference on Interaction Design and Children - IDC "10 (p. 166). New York: ACM Press. doi:10.1145/1810543.1810562 